\title{
EFEITO DA VINHAÇA NO DESENVOLVIMENTO INICIAL DE GIRASSOL, MAMONA E AMENDOIM EM CASA DE VEGETAÇÃO (1)
}

\author{
NILZA PATRÍCIA RAMOS $\left({ }^{2 *}\right)$; MARIA DO CARMO DE SALVO SOARES NOVO $\left({ }^{3}\right)$; \\ MARIA REGINA GONÇALVES UNGARO $\left({ }^{4}\right)$; ANTONIO AUGUSTO DO LAGO $\left({ }^{5}\right)$; \\ GUILHERME CALDERARI MARIN $\left({ }^{4}\right)$
}

\begin{abstract}
RESUMO
O trabalho teve como objetivo verificar o efeito da aplicação ao solo da vinhaça, resíduo da indústria canavieira, na emergência de plântulas e no desenvolvimento inicial de girassol, mamona e amendoim - culturas com potencial de utilização na sucessão com a cana-de-açúcar. O experimento foi desenvolvido em vasos com terra, dispostos em blocos ao acaso, sendo cada espécie avaliada individualmente, em esquema fatorial $2 \times 3$, em quatro repetições. Os tratamentos originaram-se de combinações da aplicação ou não da vinhaça $\left(150 \mathrm{~m}^{3} \mathrm{ha}^{-1}\right)$ sobre três cultivares de girassol (IAC Iarama, Catissol e Hélio 358), de mamona (Guarani, Íris e IAC 2028) e de amendoim (IAC Caiapó, Runner IAC 886 e Tatu). Determinaramse a velocidade de emergência de plântulas, a primeira contagem e a porcentagem final de emergência, além do comprimento e biomassa seca da parte aérea de plantas, em avaliação realizada aos 30 dias após a semeadura. Os resultados atestam que, sob condições de vegetação, a aplicação de $150 \mathrm{~m}^{3} \mathrm{ha}^{-1} \mathrm{de}^{-}$ vinhaça ao solo é prejudicial à emergência e ao desenvolvimento inicial de plantas de amendoim e em menor grau, de girassol, independentemente da cultivar estudada; para mamona, a interferência ocorre de forma positiva, principalmente sobre as variáveis relacionadas ao vigor inicial das plântulas, com melhor desempenho das cultivares IAC 2028 e Íris.
\end{abstract}

Palavras-chave: girassol, mamona, amendoim, emergência de plântulas e resíduo agroindustrial.

\section{ABSTRACT \\ OILSEED CROPS INITIAL DEVELOPMENT AS INFLUENCED BY SUGARCANE VINASSE SOIL APPLICATION}

This research aimed to verify the effect of addition to soil of vinasse, a sugarcane industry residue, on the emergence and initial development of sunflower, castorbean and peanut, which are crops with great potential of taking part of a sugarcane rotation system. The experiment, conducted in pots with soil, was a $2 \times 3$ factorial in a randomized complete block design, with four replications. The treatments consisted of application or not of $150 \mathrm{~m}^{3} \mathrm{ha}^{-1}$ of vinasse on soil sowed with sunflower (IAC-Iarama, Catisol and Hélio 358), castorbean (Guarani, Iris and IAC-2028) and peanut (IAC Caiapó, Runner IAC 886 and Tatu) cultivars. The variables evaluated were emergence speed, first count emergence, final emergence, plant height, and dry plant biomass, measured thirty days after sowing. The results show that germination and initial development of peanuts and, in a lesser degree of sunflower, are negatively influenced by the addition of vinasse to the soil, at greenhouse condition. On the other hand, the effect on castorbean is positive, mainly in relation to the vigor variables, the better performance being showed by 'IAC 2028' and 'Iris'.

Key words: sunflower, castorbean, peanut, seedling emergence, sugarcane industry residue.

$\left({ }^{1}\right)$ Recebido para publicação em 15 de janeiro de 2007 e aceito em 28 de novembro de 2007.

$\left({ }^{2}\right)$ Embrapa Meio Ambiente (CNPMA), Rodovia SP 340, Km 127,5, Caixa Postal 69, 13820.000 Jaguariúna (SP). E-mail: npramos@cnpma.embrapa.br (*) Autora para correspondência.

$\left({ }^{3}\right)$ Centro de Pesquisa e Desenvolvimento de Ecofisiologia e Biofísica, Instituto Agronômico (IAC), Caixa Postal 28, $13012-970$ Campinas (SP). E-mail: jpsnovo@iac.sp.gov.br

$\left({ }^{4}\right)$ Centro de Análise e Pesquisa Tecnológica do Agronegócio de Grãos e Fibras, IAC. E-mail: ungaro@iac.sp.gov.br, cmarin@hotmail.com.br

$\left({ }^{5}\right)$ Núcleo de Pesquisa e Desenvolvimento do Jardim Botânico, IAC. E-mail: aalago@iac.sp.gov.br 


\section{INTRODUÇÃO}

Os óleos de girassol (Helianthus annuus L.), mamona (Ricinus communis L.) e amendoim (Arachis hypogaea L.) possuem alto potencial de uso na cadeia agroenergética, pela possibilidade de aproveitamento como matéria-prima para produção de biodiesel (MAPA, 2005); o biocombustível que substitui com eficácia o óleo diesel, e reduz as emissões de gases tóxicos e particulados ao ambiente.

O aproveitamento agrícola de resíduos industriais, como a vinhaça e o bagacinho, também reforça a sustentabilidade da cadeia da cana-de-açúcar. A vinhaça presta-se como fonte de nutrientes das culturas, sendo utilizada na maioria das usinas, em doses variáveis. No solo, este resíduo eleva o $\mathrm{pH}$, o teor de matéria orgânica, a disponibilidade de alguns nutrientes, o poder de retenção dos cátions e estimula a atividade microbiana, o que pode, em alguns casos, alterar o fluxo de emergência das plantas (GLÓRIA, 1992).

O cultivo das oleaginosas em sucessão ao da cana-de-açúcar ainda é pouco estudado, assim como o efeito da vinhaça nestas culturas. MASCARENHAS et al. (1994), utilizando vinhaça $\left(50 \mathrm{~m}^{3} \mathrm{ha}^{-1}\right)$ como fonte de potássio na adubação de soja, verificaram que não houve diferença na produtividade em relação a outras fontes de fertilizantes, indicando que esta prática não interferiu significativamente no estande final da cultura e em seu estabelecimento.

AzAnia et al. (2004), trabalhando com sementes de Sida rhombifolia (guanxuma) e Brachiaria decumbens (capim-braquiária), não observaram efeito no estande final de plantas com a adição de vinhaça em doses de até $150 \mathrm{~m}^{3} \mathrm{ha}^{-1}$; porém, verificaram redução na velocidade e porcentagem de emergência de plântulas daquelas espécies, em relação ao tratamento controle, até os 20 dias, e recuperação aos 40 dias após o tratamento. BALBO JÚNIOR (1984) também observou a redução na velocidade de emergência de plântulas de Cassia tora L. (fedegoso) com a aplicação de vinhaça.

A germinação das sementes e a emergência das plântulas dependem da disponibilidade de água e oxigênio, além da faixa adequada da temperatura do substrato e em alguns casos da disponibilidade de luz, para superação de dormência (CARVALHo e NAKAGAWA, 2000); assim, qualquer condição que altere estes fatores pode prejudicar ou favorecer o fluxo de emergência das plântulas.

Diante da escassez de pesquisas que avaliem o efeito do uso de vinhaça em culturas oleaginosas, o presente trabalho teve como objetivo verificar o efeito da aplicação deste resíduo na emergência das plântulas e no desenvolvimento inicial de plantas de girassol, mamona e amendoim.

\section{MATERIAL E MÉTODOS}

O experimento foi realizado em casa de vegetação do Centro de Ecofisiologia e Biofísica do Instituto Agronômico (IAC), em Campinas (SP), durante o período de setembro a outubro de 2005. As unidades experimentais foram constituídas de vasos plásticos de 4,0 L de capacidade, contendo 2,7 L de terra fina seca ao ar peneirada sob malha de $2 \mathrm{~mm}$, proveniente de um horizonte A moderado com textura argilosa, de Latossolo Roxo, retirado de área da Fazenda Santa Elisa, em Campinas (SP), com pH $\left(\mathrm{CaCl}_{2}\right)=5,2$; matéria orgânica $=25,0 \mathrm{~g} \mathrm{dm}^{-3} ; \mathrm{P}$ (resina) $=1,0 \mathrm{mg} \mathrm{dm}^{-3} ; \mathrm{K}=0,9 ; \mathrm{Ca}=23,0 ; \mathrm{Mg}=6,0 ; \mathrm{H}+\mathrm{Al}=$ 28,0; $\mathrm{SB}=29,9 ; \mathrm{CTC}=57,7$; expressos em $\mathrm{mmol}_{\mathrm{C}} \mathrm{dm}^{-3} \mathrm{e}$ $\mathrm{V}=52 \%$. Para as culturas de amendoim, girassol e mamona, a terra foi corrigida com calcário e adubada de acordo com as recomendações de QuAGGIO E GoDor (1997), Quaggio e Ungaro (1997) e Savy Filho (1997) respectivamente. Os cálculos para calagem e adubação foram realizados com base no volume do vaso. Para a completa homogeneização da terra com o calcário e, posteriormente, com o adubo, foram realizados movimentos circulares com auxílio de um bastão de madeira, a fim de facilitar a mistura uniforme tanto em profundidade, como em área, evitando assim efeitos de salinidade desses insumos diretamente sobre as sementes.

Antes da instalação do experimento, determinou-se a caracterização inicial do potencial fisiológico do lote representante de cada cultivar. Foram utilizados o teste de germinação (BRASIL, 1992) e as determinações da velocidade e porcentagem final de emergência de plântulas, seguindo recomendações de NAKAGAWA (1999), cujos valores são apresentados na tabela 1.

O delineamento experimental utilizado foi o de blocos ao acaso, em um esquema fatorial $2 \times 3$, com quatro repetições; sendo cada espécie avaliada individualmente. Os tratamentos originaram-se das combinações da aplicação ou não da vinhaça $\left(150 \mathrm{~m}^{3}\right.$ $\mathrm{ha}^{-1}$ ) e três cultivares de girassol (IAC Iarama, Catissol e Hélio 358), de mamona (Guarani, Íris e IAC 2028) e de amendoim (IAC Caiapó, Runner IAC 886 e Tatu). Em cada vaso, foram semeadas dez sementes tratadas com Thiran $0,2 \%$, a $3 \mathrm{~cm}$ de profundidade e, posteriormente, aplicada a vinhaça com regador.

A vinhaça utilizada foi obtida da lagoa de decantação da Usina Ester, Cosmópolis (SP), com a seguinte composição química: $\mathrm{pH}=4,1 ; \mathrm{N}$ total $=50,1$; $\mathrm{N}$ amoniacal $=0,4 ; \mathrm{N}$ nitrato $=0,2 ; \mathrm{N}$ nitrito $=24,4 ;$ $\mathrm{PO}_{4}$ total $=1.513,0 ; \mathrm{K}=1.477,0 ; \mathrm{Ca}=525,0 ; \mathrm{Mg}=$ 1435,0; $\mathrm{SO}_{4}=99,6$; expressos em mg L $\mathrm{me} \mathrm{CE}^{-1}=5,8 \mathrm{dS}$ $\mathrm{m}^{-1}$. As análise de $\mathrm{N}$ total (Kjeldahl), $\mathrm{N}$ amoniacal, 
nitrato e nitrito foram realizadas empregando-se destilação por arraste a vapor, segundo métodos descritos por BAtAgLia et al. (1978) e ABreu et al. (2006).

As variáveis determinadas foram: velocidade de emergência, mediante a contagem diária do número de plântulas identificadas como normais, até a estabilização desse número, com o cálculo do índice de velocidade (IVE), com base em MaGuire (1962), além da primeira contagem (PCE) e porcentagem final (EM) de emergência de plântulas (BRASIL, 1992). Também, foram determinados, aos 30 dias após a semeadura, o comprimento da parte aérea de planta (CPAP) e a biomassa seca (BSPA) da parte aérea.

Tabela 1. Caracterização inicial do potencial fisiológico dos lotes das sementes das cultivares de girassol, mamona e amendoim, quanto à germinação (TG), emergência final (EM) e índice de velocidade de emergência de plântulas (IVE). Campinas (SP), 2005

\begin{tabular}{lccc}
\hline Cultivares & TG & EM & IVE \\
\cline { 2 - 4 } & \multicolumn{3}{c}{ Girassol } \\
\hline IAC-Iarama & $99,1 \mathrm{a}$ & $100,0 \mathrm{a}$ & $1,7 \mathrm{a}$ \\
Catissol & $95,2 \mathrm{a}$ & $100,0 \mathrm{a}$ & $1,7 \mathrm{a}$ \\
Hélio 358 & $98,0 \mathrm{a}$ & $100,0 \mathrm{a}$ & $1,5 \mathrm{a}$ \\
\hline & \multicolumn{3}{c}{ Mamona } \\
\hline Guarani & $80,0 \mathrm{~b}$ & $78,2 \mathrm{a}$ & $0,6 \mathrm{a}$ \\
IAC 2028 & $96,3 \mathrm{a}$ & $70,0 \mathrm{a}$ & $0,5 \mathrm{a}$ \\
Íris & $92,2 \mathrm{a}$ & $71,0 \mathrm{a}$ & $0,6 \mathrm{a}$ \\
\hline & & Amendoim \\
\hline IAC-Caiapó & $88,0 \mathrm{~b}$ & $86,4 \mathrm{a}$ & $1,0 \mathrm{a}$ \\
Runner IAC 886 & $92,1 \mathrm{a}$ & $82,8 \mathrm{a}$ & $0,9 \mathrm{a}$ \\
Tatu & $97,0 \mathrm{a}$ & $83,9 \mathrm{a}$ & $1,0 \mathrm{a}$ \\
\hline
\end{tabular}

Médias seguidas pela mesma letra na coluna não diferem entre si pelo teste de Duncan a 5\% de probabilidade.

Os dados obtidos por espécie foram submetidos à análise de variância com aplicação do teste F. Quando significativas, as médias foram comparadas pelo teste de Duncan a $5 \%$ de probabilidade. Os dados em porcentagem de emergência e emergência final foram transformados em arco seno $\sqrt{x / 100}$. Para a primeira contagem de emergência a transformação usada foi $\sqrt{x / 100}$.

\section{RESULTADOS E DISCUSSÃO}

A caracterização preliminar do potencial fisiológico dos lotes de sementes das cultivares de girassol, mamona e amendoim está indicada na Tabela 1. Em todos os lotes observou-se germinação acima do padrão exigido para a comercialização como sementes, sendo a média para girassol de $97 \%$, para mamona de $89 \%$ e para amendoim de $92 \%$. Para taxa de germinação, houve diferença significativa entre os lotes das cultivares de mamona e de amendoim, com pior desempenho da 'Guarani' (80\%) e 'IAC Caiapó' (88\%), para cada espécie respectivamente. Esta menor germinação inicial pode comprometer o desempenho frente aos lotes das demais cultivares, principalmente, sob condições adversas de campo.

Os valores de velocidade e porcentagem de emergência de plântulas em solo, referentes ao vigor de sementes (Tabela 1), não revelaram diferenças entre cultivares, para nenhuma das espécies estudadas. No girassol, o vigor foi alto, inclusive com máximo desempenho na emergência de plântulas $(100,0 \%)$, o que demonstra a elevada qualidade das sementes dos lotes em estudo. Por outro lado, nos lotes de mamona ocorreu menor desempenho, em comparação ao teste de germinação, principalmente para 'IAC-2028' e 'Íris', com germinação superior a $90 \%$ e resultaram em valores de $70 \%$ de emergência de plântulas. O amendoim apresentou tendência semelhante ao da mamona, com redução dos valores nos testes de vigor. Nas oleaginosas são comuns valores de emergência de plântulas inferiores aos de germinação, em função das reservas na forma de ácidos graxos, mais sujeitas às degradações oxidativas (CARvalHo e NAKAGaWA, 2000) e aos patógenos que afetam o vigor.

Nas três espécies estudadas, a fonte de variação Cultivares não foi significativa para a maioria das variáveis (Tabela 2), exceção para CPAP em amendoim e BSPA em girassol. Essas diferenças, apenas nas variáveis relativas ao crescimento de plantas, demonstram que as cultivares, embora semelhantes na fase de emergência de plântulas, começam a se diferenciar logo aos 30 dias após a semeadura. Por outro lado, o tratamento relativo à adição de vinhaça alterou o desempenho do girassol e do amendoim para todas as variáveis, não afetando o crescimento da mamona.

Com relação à interação entre cultivares e aplicação da vinhaça (Tabela 2) não houve efeito significativo para a maioria das variáveis analisadas nas três espécies, revelando que o comportamento das cultivares foi constante, independentemente da aplicação deste resíduo. Entretanto, para a mamona, a interação foi positiva nos resultados do comprimento da parte aérea e da biomassa seca da parte aérea de plantas, visto que esta última variável também se alterou no amendoim. MARCOS FiLHO (1999) relatou que o potencial fisiológico inicial das sementes interfere no desempenho de plantas em campo, principalmente sob condições de estresse. Assim, a presença da vinhaça provavelmente influenciou as variáveis relativas ao crescimento de plantas, como CPAP e BSPA. 
Tabela 2. Quadrados médios do índice de velocidade de emergência de plântulas (IVE), porcentagens de emergência final (EM) e da primeira contagem de emergência (PCE), comprimento da parte aérea de plantas (CPAP) e biomassa seca da parte aérea de plantas (BSPA), em casa de vegetação, com as culturas do girassol, da mamona e do amendoim. Campinas (SP), 2005

\begin{tabular}{|c|c|c|c|c|c|c|}
\hline Fatores & GL & IVE & EM & PCE & CPAP & BSPA \\
\hline & \multicolumn{6}{|c|}{ Girassol } \\
\hline Cultivares (C) & 2 & $0,11^{\text {n.s. }}$ & $99,12^{\text {n.s. }}$ & $6,09^{\text {n.s. }}$ & $5,38^{\text {n.s. }}$ & $0,69^{* *}$ \\
\hline Vinhaça (V) & 1 & $2,22^{* *}$ & $980,93^{* *}$ & $138,93^{* *}$ & $126,04^{* *}$ & $1,45^{* *}$ \\
\hline $\mathrm{C} \times \mathrm{V}$ & 2 & $0,01^{\text {n.s. }}$ & $99,12^{\text {n.s. }}$ & $6,98^{\text {n.s. }}$ & $1,04^{\text {n.s. }}$ & $0,05^{\text {n.s. }}$ \\
\hline \multirow[t]{2}{*}{ CV (\%) } & & 10,68 & 8,71 & 24,09 & 9,96 & 11,00 \\
\hline & \multicolumn{6}{|c|}{ Mamona } \\
\hline Cultivares (C) & 2 & $0,02^{\text {n.s. }}$ & $112,62^{\text {n.s. }}$ & $4,31^{\text {n.s. }}$ & $1,63^{\text {n.s. }}$ & $0,17^{\text {n.s. }}$ \\
\hline Vinhaça (V) & 1 & $0,04^{\text {n.s. }}$ & $125,34^{\text {n.s. }}$ & $1,07^{\text {n.s. }}$ & $92,04^{\text {n.s. }}$ & $0,05^{\text {n.s. }}$ \\
\hline $\mathrm{C} \times \mathrm{V}$ & 2 & $0,01^{\text {n.s. }}$ & $6,53^{\text {n.s. }}$ & $1,87^{\text {n.s. }}$ & $14,29^{*}$ & $1,70^{*}$ \\
\hline \multirow[t]{2}{*}{$\mathrm{CV}(\%)$} & & 37,95 & 27,69 & 86,81 & 10,20 & 17,47 \\
\hline & \multicolumn{6}{|c|}{ Amendoim } \\
\hline Cultivares (C) & 2 & $0,01^{\text {n.s. }}$ & $14,88^{\text {n.s. }}$ & $1,37^{\text {n.s. }}$ & $5,38^{*}$ & $0,25^{\text {n.s. }}$ \\
\hline Vinhaça (V) & 1 & $2,03^{* *}$ & $5150,92^{* *}$ & $103,26^{* *}$ & $126,04^{* *}$ & $20,13^{* *}$ \\
\hline $\mathrm{C} \times \mathrm{V}$ & 2 & $0,03^{\text {n.s. }}$ & $0,91^{\text {n.s. }}$ & $5,07^{\text {n.s. }}$ & $1,04^{\text {n.s. }}$ & $4,95^{* *}$ \\
\hline $\mathrm{CV}(\%)$ & & 24,36 & 28,02 & 35,29 & 6,45 & 22,64 \\
\hline
\end{tabular}

${ }^{*, * *}$ : significativo pelo teste de Duncan a $1 \%$ e $5 \%$ de probabilidade respectivamente; ${ }^{\text {ns: }}$ não significativo.

Na tabela 3, pode-se observar que não houve diferença significativa na emergência de plântulas entre as cultivares estudadas, para nenhuma das oleaginosas. No girassol, houve diferença entre as cultivares apenas para BSPA, com desempenho superior de 'Hélio 358' em relação às demais. No amendoim, houve diferença no comprimento da parte aérea de plantas, com melhor desempenho da cultivar Tatu, amplamente cultivada no passado em áreas de sucessão com a cana-de-açúcar, no nordeste paulista. Essa cultivar possui hábito de crescimento ereto, que justifica a sua superioridade em comprimento em relação ao 'IAC-Caiapó' e ao 'Runner IAC-886', ambas com hábito rasteiro. Em mamona não ocorreram diferenças entre as cultivares nas variáveis analisadas.

De forma geral, as cultivares de girassol se destacaram positivamente quanto à emergência e ao crescimento de plantas, em comparação ao amendoim e mamona. A comparação interespecífica deve ser vitada, porém considerações a respeito do esempenho inicial de plantas auxiliam a recomendação de uma ou outra espécie a ser semeada, em condições adversas de campo.

A vinhaça influenciou negativamente todas as variáveis em girassol e amendoim (Tabela 4), indicando ação inibitória deste resíduo sobre o desenvolvimento inicial destas culturas, enquanto na mamona não foram observadas alterações. A primeira variável afetada foi IVE, provavelmente em função das alterações químicas provocadas pela adição da vinhaça nas áreas próximas às sementes. A vinhaça promove a elevação do $\mathrm{pH}$ no solo (LeAL, 1983) e modifica, principalmente, a concentração de nutrientes como potássio, magnésio e cálcio, pois é rica nestes nutrientes, além de alterar o teor de matéria orgânica, o poder de retenção de cátions e a capacidade de retenção de água (Quintela et al., 2002).

A maior concentração de sais na solução do solo pode originar um potencial osmótico mais elevado em torno das sementes, atrasando o processo germinativo e a emergência de plântulas. Entretanto, esses efeitos também estão associados com as características do solo, como demonstrou BRITO et al. (2005) avaliando o efeito da aplicação de 350 e 700 $\mathrm{m}^{3} \mathrm{ha}^{-1}$ de vinhaça no desenvolvimento de plantas. Esses autores observaram que solos com alto teor de argila, como é o caso desse experimento, poderiam adsorver grande parte do potássio da vinhaça, não causando danos às plantas, mesmo quando aplicado em doses mais elevadas.

A velocidade de emergência de plântulas, devido à aplicação da vinhaça, foi diminuída em $37,2 \%$ no girassol e em $29,5 \%$ no amendoim (Tabela 4). A redução pode ter sido mais pronunciada nas cultivares de girassol pelo tipo de semente dessa espécie, que é protegida pelo pericarpo fibroso do fruto 
do tipo aquênio (KNowles, 1978), o qual demanda elevada quantidade de água para iniciar a germinação. Assim, com a menor disponibilidade de água no solo, promovida pelo aumento do potencial osmótico causado pela vinhaça, a germinação foi mais lenta. Entretanto, essa proteção pode ser benéfica, reduzindo provavelmente a entrada de excesso de sais para o interior das sementes.

$\mathrm{Na}$ cultura do amendoim, mesmo que o atraso na emergência tenha sido inferior à do girassol, os prejuízos podem ser mais drásticos, pois quanto maior o tempo em que as sementes ficam sujeitas à ação dos patógenos de solo, maior a possibilidade de degradação do eixo embrionário, pois o embrião possui a radícula bastante exposta. BALBO JÚNIOR (1984) e AzAnia et al. (2004), avaliando sementes de plantas daninhas, também observaram atrasos na emergência com a aplicação de vinhaça ao solo.

Com relação à emergência de plântulas (Tabela 4), os efeitos da vinhaça foram mais pronunciados na cultura do amendoim, com redução de $56,4 \%$ em relação ao controle. Reduções na emergência de Digitaria horizontalis, Cyperus rotundus, S. rhombifolia e Emilia sonchifolia, também foram observadas em solos tratados com diferentes doses de vinhaça (Christoffoleti e BAcChi, 1985). No girassol, a redução foi de apenas $4,9 \%$; entretanto, outras variáveis foram bem mais afetadas, como a primeira contagem de plântulas (PCE) que teve queda de $74,2 \%$, em relação ao tratamento sem vinhaça. Este resultado, juntamente com o de IVE, mostra que para o girassol o atraso na emergência foi o principal prejuízo promovido pela aplicação de vinhaça, pois atrasou o desenvolvimento de plantas, reduzindo CPAP e BSPA, mas não alterou substancialmente o estande final da cultura. Também, AzAnia et al. (2004) observaram que o efeito deletério da vinhaça em S. rhombifolia ocorreu até aproximadamente 20 dias após sua aplicação, no entanto, aos 40 dias as plantas estabeleceram-se de forma semelhante aos tratamentos-controle.

$\mathrm{Na}$ cultura da mamona, não foi observado efeito significativo da aplicação da vinhaça sobre a emergência e o desenvolvimento inicial de plantas (Tabela 2 e 4), significando que o resíduo pode ser aplicado até a dose de $150 \mathrm{~m}^{3}$ ha $^{-1}$ no seu cultivo. A camada espessa de células $(200 \mathrm{~mm})$ lignificadas, fibrosas e intensamente aderidas ao endosperma, presente logo abaixo do tegumento rígido (Moskin, 1986), pode funcionar como um filtro, que poderia reduzir a passagem de moléculas de maior peso molecular para o interior das sementes de mamona, incluindo-se possíveis solutos tóxicos presentes na vinhaça. Neste contexto, Welbaum e Bradford (1990) observaram que as sementes de melão podem ser embebidas em soluções salinas de alta concentração, sem danos celulares, por possuírem tecidos semipermeáveis envolvendo o embrião, assim como as de tomate, alface e pimentão, enquanto nas sementes de brócolo os tecidos são permeáveis a sais (Welbaum et al., 1998), com intoxicação celular.

Tabela 3. Índice de velocidade de emergência de plântulas (IVE), porcentagens de emergência final (EM) e primeira contagem (PCE), comprimento da parte aérea de plantas (CPAP) e biomassa seca da parte aérea de plantas (BSPA), em função das cultivares utilizadas, em experimento desenvolvido em casa de vegetação com as culturas do girassol, da mamona e do amendoim. Campinas (SP), 2005

\begin{tabular}{|c|c|c|c|c|c|}
\hline Cultivar & IVE & EM & PCE & CPAP & BSPA \\
\hline & & \multicolumn{2}{|c|}{$\%$} & $\mathrm{~cm}$ & $\mathrm{~g}$ \\
\hline & \multicolumn{5}{|c|}{ Girassol } \\
\hline IAC Iarama & $1,3 a$ & $99,0 \mathrm{a}$ & $56,2 \mathrm{a}$ & $19,4 \mathrm{a}$ & $1,4 \mathrm{~b}$ \\
\hline Catissol & $1,4 \mathrm{a}$ & $99,7 \mathrm{a}$ & $68,0 \mathrm{a}$ & $20,0 \mathrm{a}$ & $1,2 \mathrm{c}$ \\
\hline \multirow[t]{2}{*}{ Hélio 358} & $1,2 \mathrm{a}$ & $96,8 \mathrm{a}$ & $42,2 \mathrm{a}$ & $21,0 \mathrm{a}$ & $1,7 \mathrm{a}$ \\
\hline & \multicolumn{5}{|c|}{ Mamona } \\
\hline Guarani & $0,6 a$ & $76,1 \mathrm{a}$ & $0,6 a$ & $15,4 \mathrm{a}$ & $2,9 a$ \\
\hline IAC 2028 & $0,5 \mathrm{a}$ & $64,9 a$ & $0,6 a$ & $16,3 a$ & $3,1 \mathrm{a}$ \\
\hline \multirow[t]{2}{*}{ Íris } & $0,6 a$ & $67,3 a$ & $4,8 \mathrm{a}$ & $16,0 \mathrm{a}$ & $3,2 \mathrm{a}$ \\
\hline & \multicolumn{5}{|c|}{ Amendoim } \\
\hline IAC Caiapó & $0,7 \mathrm{a}$ & $64,6 \mathrm{a}$ & $8,1 \mathrm{a}$ & $13,9 b$ & $4,2 \mathrm{a}$ \\
\hline Runner IAC 886 & $0,6 a$ & $60,8 \mathrm{a}$ & $7,3 a$ & $14,3 b$ & $4,5 a$ \\
\hline Tatu & $0,7 \mathrm{a}$ & $60,4 a$ & $12,3 a$ & $18,1 \mathrm{a}$ & $4,5 a$ \\
\hline
\end{tabular}

Médias seguidas pela mesma letra na coluna não diferem entre si pelo teste de Duncan a $5 \%$ de probabilidade. 
Tabela 4. Índice de velocidade de emergência de plântulas (IVE), porcentagens de emergência final (EM) e primeira contagem (PCE), comprimento da parte aérea de plantas (CPAP) e biomassa seca da parte aérea de plantas (BSPA), em função da aplicação ou não de vinhaça ao solo, em experimento desenvolvido em casa de vegetação com as culturas de girassol, mamona e amendoim. Campinas (SP), 2005

\begin{tabular}{|c|c|c|c|c|c|}
\hline Variáveis & IVE & $\mathrm{EM}$ & PCE & CPAP & BSPA \\
\hline & & \multicolumn{2}{|c|}{$\%$} & $\mathrm{~cm}$ & $\mathrm{~g}$ \\
\hline & & & Girassol & & \\
\hline Sem vinhaça & $1,6 a$ & $100,0 a$ & $96,6 a$ & $22,4 \mathrm{a}$ & $1,7 \mathrm{a}$ \\
\hline \multirow[t]{2}{*}{ Com vinhaça } & $1,0 \mathrm{~b}$ & $95,1 b$ & $24,9 b$ & $17,8 b$ & $1,2 b$ \\
\hline & & & Mamona & & \\
\hline Sem vinhaça & $0,6 a$ & $73,1 \mathrm{a}$ & $2,3 a$ & $13,9 a$ & $3,1 \mathrm{a}$ \\
\hline \multirow[t]{2}{*}{ Com vinhaça } & $0,5 a$ & $65,8 \mathrm{a}$ & $1,0 \mathrm{a}$ & $17,8 \mathrm{a}$ & $3,0 \mathrm{a}$ \\
\hline & & & Amendoim & & \\
\hline Sem vinhaça & $1,0 \mathrm{a}$ & $84,2 a$ & $26,3 a$ & $18,6 a$ & $5,3 a$ \\
\hline Com vinhaça & $0,7 \mathrm{~b}$ & $36,7 b$ & $0,6 b$ & $1,3 b$ & $3,5 b$ \\
\hline
\end{tabular}

Médias seguidas de mesma letra na coluna não diferem entre si pelo teste de Duncan a $5 \%$ de probabilidade.

Na cultura da mamona (Tabela 5), a vinhaça proporcionou alongamento da parte aérea de plantas, nas cultivares IAC 2028 e Îris, sem alterações significativas na cultivar Guarani, sendo a 'IAC-2028' mais favorecida na presença deste resíduo. Com aplicação da vinhaça, SENGIK et al. (1996) verificaram acréscimos na produção de massa seca de raízes e da parte aérea de plantas de sorgo com 30 dias de idade.

Em amendoim, foi observada significância para a interação de Cultivares e Vinhaça para BSPA (Tabela 5). Comparando-se as cultivares no tratamento sem vinhaça, verificou-se em 'IAC Caiapó' menor massa seca da parte aérea que nas demais; a massa, porém, não foi reduzida com a aplicação de vinhaça, revelando que esta cultivar não é afetada em termos de produção de biomassa, enquanto as outras tiveram reduções de até $47 \%$. Entretanto, não se pode afirmar que exista relação entre cultivares de amendoim e aplicação de vinhaça para o desenvolvimento inicial da cultura utilizando-se apenas uma variável como referência. O que se observa é um efeito negativo da aplicação deste resíduo sobre o desenvolvimento inicial das plantas; estudos posteriores, envolvendo todo o ciclo do amendoim, da mamona e do girassol, devem ser realizados visando à produtividade de grãos.

O uso de resíduo industrial como a vinhaça deve ser valorizado pela possibilidade de redução da contaminação de águas superficiais, de lençóis freáticos e do ambiente em geral (Voll, 2005). No entanto, ficam evidentes, com base nos dados apresentados, as diferenças no comportamento de plantas em função da espécie. Esse fato, associado à escassez de informações nesta linha de pesquisa, reforça a necessidade de continuidade deste trabalho, procurando a maior sustentabilidade dos sistemas agrícolas.

Tabela 5. Comprimento da parte aérea (CPAP) e biomassa seca da parte aérea de plantas (BSPA), em função da interação genótipos e aplicação ou não de vinhaça ao solo, em experimentos desenvolvidos em casa de vegetação com a cultura da mamona e do amendoim. Campinas (SP), 2005

\begin{tabular}{lcccc}
\hline Mamona & Variável & Guarani & IAC 2028 & Íris \\
\hline Sem vinhaça & CPAP $(\mathrm{cm})$ & $14,3 \mathrm{Aa}$ & $12,8 \mathrm{Ab}$ & $14,8 \mathrm{Ab}$ \\
Com vinhaça & & $16,5 \mathrm{Ba}$ & $19,8 \mathrm{Aa}$ & $17,3 \mathrm{Ba}$ \\
Sem vinhaça & BSPA $(\mathrm{g})$ & $3,5 \mathrm{Aa}$ & $2,9 \mathrm{Aa}$ & $2,9 \mathrm{Aa}$ \\
Com vinhaça & & $2,3 \mathrm{Bb}$ & $3,5 \mathrm{Aa}$ & $3,3 \mathrm{Aa}$ \\
\hline Amendoim & & IAC Caiapó & Runner IAC 886 & Tatu \\
Sem vinhaça & BSPA $(\mathrm{g})$ & $4,2 \mathrm{Ba}$ & $5,9 \mathrm{Aa}$ & $3,9 \mathrm{Aa}$ \\
Com vinhaça & & $4,2 \mathrm{Aa}$ & $3,1 \mathrm{Ab}$ & $3,1 \mathrm{Ab}$ \\
\hline
\end{tabular}

Médias seguidas de mesma letra maiúscula na linha e minúscula na coluna não diferem entre si pelo teste de Duncan a $5 \%$ de probabilidade. 


\section{CONCLUSÕES}

1. A aplicação correspondente a $150 \mathrm{~m}^{3} \mathrm{ha}^{-1}$ de vinhaça, em experimento implantado em vasos com $2,7 \mathrm{~L}$ de terra, é prejudicial à emergência das plântulas e ao desenvolvimento inicial de amendoim e de girassol, independentemente da cultivar.

2. Para a mamona, a interferência ocorre positivamente, principalmente sobre as variáveis relacionadas ao vigor, com melhor desempenho das cultivares IAC 2028 e Íris.

\section{AGRADECIMENTOS}

Ao Programa de Pesquisa em Amendoim do IAC, na pessoa do pesquisador Dr. Eder Jorge de Oliveira, pela doação das sementes de amendoim utilizadas neste experimento.

\section{REFERÊNCIAS}

ABREU, M.F.; ANDRADE, J.C.; FALCÃO, A.A. Protocolo de análises químicas. In: ANDRADE, J.C.; ABREU, M.F. (Ed.). Análise química de resíduos sólidos para monitoramento e estudos agroambientais. Instituto Agronômico: Campinas. 2006. p.121-158.

AZANIA, A.A.P.M.; AZANIA, C.A.M.; MARQUES, M.O.; PAVANI, M.C.M.D. Emergência e desenvolvimento de guanxuma (Sida rhombifolia), capim-braquiária (Brachiaria decumbens) e cana-de-açúcar (Saccharum spp.) influenciados por subprodutos da destilação do álcool. Planta Daninha, Viçosa, v.22, n.3, p.331-336, 2004.

BALBOJÚNIOR, L. Estudos preliminares dos efeitos da vinhaça sobre a emergência e desenvolvimento inicial de plantas daninhas. I - Fedegoso (Cassia tora L.). 41 f. 1984. Monografia (Trabalho de graduação em Agronomia) - FCAV/ Universidade Estadual Paulista, Jaboticabal, 1984.

BATAGLIA, O.C.; TEIXEIRA, J.P.; FURLANI, P.R.; FURLANI, A.M.C.; GALLO, J.R. Métodos de análise química de plantas. Instituto Agronômico: Campinas, 1978. 31p. (Circular técnica, 78).

BRASIL. Ministério da Agricultura e Reforma Agrária. Regras para análise de sementes. Brasília: AGIPLAN, 1992. 365p.

BRITO, F.L.; ROLIM, M.M.; PEDROSA, E.M.R. Teores de potássio e sódio no lixiviado e em solos após a aplicação de vinhaça. Revista Brasileira de Engenharia Agrícola e Ambiental, v.9, suplemento, p.52-56, 2005.

CARVALHO, N.M.; NAKAGAWA, J. Sementes: ciência, tecnologia e produção. Jaboticabal: FUNEP, 2000. 650p.

CHRISTOFFOLETI, P.J.; BACCHI, O.O.S. Efeito da aplicação de vinhaça sobre a população e controle químico das plantas daninhas na cultura da cana-de-açúcar (Saccharum spp). Planta Daninha, Viçosa, v.8, n.1/2, p.60-70, 1985.

GLÓRIA, N.A. Uso agronômico de resíduos. In: REUNIÃO BRASILEIRA DE FERTILIDADE DO SOLO E NUTRIÇÃO DE PLANTAS, 20, 1992. Piracicaba. Anais... Piracicaba: ESALQ/ USP, 1992. p.1-17.

KNOWLES, P.E. Morphology and anatomy. In: CARTER, J. F. (Ed.). Sunflower science and technology. Madison: ASA, 1978. p.55-88.

LEAL, J. R. Potencial redox e pH: variações em um solo tratado com vinhaça. Revista Brasileira de Ciência do Solo, Campinas, v.7, p.257-261, 1983.

MAGUIRE, J.D. Speed of germination aid in selection and evaluation for seedling and vigor. Crop Science, Madison, v.2, n.2, p.176-177, 1962.

MARCOS FILHO, J. Introdução. In: KRZYZANOWSKI, F.C.; VIEIRA, R.D.; FRANÇA NETO, J.B. (Ed). Vigor de sementes: conceitos e testes. Londrina: ABRATES, p.1-1 - 3-20, 1999.

MASCARENHAS, H.A.A.; TANAKA, R.T.; PEREIRA, J.C.V.N.A.; GALLO, P.B.; BATAGLIA, O.C. Efeito de adubos potássicos na produção de soja. Scientia Agricola, Piracicaba, v.51, p.82-89, 1994.

MINISTÉRIO DA AGRICULTURA, PECUÁRIA E ABASTECIMENTO. Plano Nacional de Agroenergia. Brasília, 118 p. 2005.

MOSKIN, V.A. Castor. New Delhi: Amerind, 1986. p.11-64.

NAKAGAWA, J. Testes de vigor baseados no desempenho de plântulas. In: KRZYZANOWSKI, F.C.; VIEIRA, R.D.; FRANÇANETO, J.B. Vigor de sementes: conceitos e testes. Londrina:ABRATES, 1999. p.(2.1)-(2.24).

QUAGGIO. J.A. ; GODOY, I.J. Amendoim. In: RAIJ, B.; CANTARELLA, H.; QUAGGIO, J.A.; FURLANI, A.M.C. Recomendações de adubação e calagem para o estado de São Paulo, $2^{\mathrm{a}}$ ed. Campinas, Instituto Agronômico ; Fundação IAC, 1997. p.192.

QUAGGIO. J.A. ; UNGARO, M.R.G. Girassol. In: RAIJ, B.; CANTARELLA, H.; QUAGGIO, J.A.; FURLANI, A.M.C. Recomendações de adubação e calagem para o estado de São Paulo, $2^{a}$ ed. Campinas, Instituto Agronômico/Fundação IAC, 1997. p.198.

QUINTELA, A.C.R.; ANDRADE, L.A.B.; CORREAA, J.B.D.; RESENDE, P.M.; VIEIRA, G.G. Controle de plantas daninhas em cana crua (cultivar RB835089) no sistema integrado palhiço, herbicida e vinhaça. STAB, Piracicaba, v.20, p.3842, 2002.

SAVY FILHO, A. Mamona. In: RAIJ, B.; CANTARELLA, H.; QUAGGIO, J.A.; FURLANI, A.M.C. Recomendações de adubação e calagem para o estado de São Paulo, 2.ed. Campinas, Instituto Agronômico/Fundação IAC, 1997. p.201 
SENGIK, E.; CANA, M.A.O.;SILVA, C.C.; RIBEIRO, A.C. Efeitos da vinhaça sobre o crescimento do sorgo granífero. In: UNIVERSIDADE ESTADUAL DE MARINGÁ, CENTRO DE CIÊNCIAS AGRÁRIAS. Anuário CCA.... 1995/1996. Maringá. p.163-166, 1996.

VOLL, C.E. Aplicação da vinhaça e do extrato de palhiço de cana-de-açúcar no controle de plantas daninhas. 45p. 2005. Dissertação (Mestrado) - Escola Superior de Agricultura Luiz de Queiroz, Piracicaba, 2005.

WELBAUM, G.E.; SHEN, Z.; OLUOCH, M.O.; JETT, L.W. The evolution and effects of priming vegetables seeds. Seed Technology, v.20, n.2, p.209-235, 1998.

WELBAUM, G.E.; BRADFORD, K.J. Water relations of seeds development and germination in muskmelon (Cucumis melo L.). IV. Characteristics of perisperm during development. Plant Physiology, Sofia, v.92, p.1038-1045, 1990. 